Note

\title{
Group Size and Social Conflict in Complex Societies
}

\author{
Sheng-Feng Shen, ${ }^{1, \star}$ Erol Akçay, ${ }^{2,3}$ and Dustin R. Rubenstein ${ }^{4}$ \\ 1. Biodiversity Research Center, Academia Sinica, Taipei 115, Taiwan; 2. Department of Ecology and Evolutionary Biology, Princeton \\ University, Princeton, New Jersey 08544; 3. Department of Biology, University of Pennsylvania, Philadelphia, Pennsylvania 19104; \\ 4. Department of Ecology, Evolution, and Environmental Biology, Columbia University, New York, New York 10027
}

Submitted May 1, 2013; Accepted September 17, 2013; Electronically published December 10, 2013

\begin{abstract}
Conflicts of interest over resources or reproduction among individuals in a social group have long been considered to result in automatic and universal costs to group living. However, exploring how social conflict varies with group size has produced mixed empirical results. Here we develop a model that generates alternative predictions for how social conflict should vary with group size depending on the type of benefits gained from being in a social group. We show that a positive relationship between social conflict and group size is favored when groups form primarily for the benefits of sociality but not when groups form mainly for accessing groupdefended resources. Thus, increased social conflict in animal societies should not be viewed as an automatic cost of larger social groups. Instead, studying the relationship between social conflict and the types of grouping benefits will be crucial for understanding the evolution of complex societies.
\end{abstract}

Keywords: group size, social conflict, cooperative breeding, eusociality, sociality.

\section{Introduction}

Animals living in social groups receive a number of direct and indirect benefits, but they must also pay a variety of costs (Alexander 1974). One of the primary costs associated with living in groups of genetically distinct organisms is the cost associated with conflicts of interest over resources or the distribution of reproduction among individuals in a social group. We define conflicts of interest as situations in which there is a possibility of some individuals increasing their fitness at the expense of other individuals (Ratnieks and Reeve 1992; Godfray 1995). Conflicts of interest can be a repulsive force for the evolution of group living because they frequently generate selection for costly harming behaviors aimed at securing a larger share of reproduction or group resources (Reeve 2000; Queller and Strassmann 2009). We define the realization of such costly behaviors as social conflict. Social

\footnotetext{
* Corresponding author; e-mail: shensf@sinica.edu.tw.

Am. Nat. 2014. Vol. 183, pp. 301-310. (C) 2013 by The University of Chicago. 0003-0147/2014/18302-54641\$15.00. All rights reserved. DOI: $10.1086 / 674378$
}

conflict may occur at all levels of biological organization and reduce (or even negate) the benefits of sociality. Therefore, determining the factors that influence levels of conflict within groups is central for not only studying the evolution of complex societies (Krause and Ruxton 2002; Bourke 2011) but also for understanding other major evolutionary transitions, such as the transition from single cellularity to multicellularity (Maynard-Smith and Szathmary 1997; Calcott and Sterelny 2011).

Social conflict has been considered an automatic and universal cost of group living because the level of social conflict is often assumed to increase with the number of competing individuals in a group (Alexander 1974). However, empirical studies of animal societies have generally failed to produce consistent relationships between group size and social conflict (Monnin et al. 2003; Clutton-Brock et al. 2008; Mileva et al. 2009; Amsalem and Hefetz 2011). This failure to identify consistent patterns may occur because other social factors (e.g., the fitness benefits to grouping) and ecological factors (e.g., the level of available group resources) may also vary with group size and influence levels of social conflict. As a result, the relationship between group productivity and group size could vary among species because groups form for varying types of benefits in different organisms. For example, some animals form social groups to access fixed resources. In these cases (e.g., carcass sharing in burying beetles; Eggert and Muller 1997; Robertson et al. 1998), per capita productivity will decrease with increasing group size, whereas total group productivity remains constant. In contrast, many social animals form groups because living in a group by itself has some benefit, such as predator avoidance or detection (Alexander 1974). In these cases (e.g., cooperative breeding in lions; VanderWaal et al. 2009), group productivity may increase with increasing group size until reaching the most productive size, at which point it may decrease. Thus, to fully understand the nature of social conflict within complex societies, one must also consider the type of benefits obtained from group living and how these benefits vary with group size. 
Few theoretical models have explicitly addressed the relationship between social conflict and group size. Most theoretical works modeling how social and ecological factors influence social conflict either are simple two-player models (Johnstone 2000; Shen and Reeve 2010; Cant 2012) or do not consider the effect of group size (Frank 1995; Foster 2004; but see Reeve and Hölldobler 2007, which modeled within-group conflict in the context of betweengroup competition). Thus, the general relationships among group size, group productivity, and social conflict remain largely unexplored theoretically, and given the mixed empirical evidence of a consistent relationship between group size and social conflict, better predictive models are clearly needed. Here we construct an evolutionary game-theoretic model to investigate the relationship between social conflict and group size under different ecological and social conditions. Using our model, we derive key predictions that can be tested in group-living vertebrates and invertebrates to better understand how social and ecological factors impact animal social evolution.

\section{The Model}

The Model Framework (see fig. 1)

We begin by explicitly defining social conflict as any act that increases the initiator's share of the group resources at the expense of other interacting individuals (Reeve 2000). Our definition includes contest competition (e.g., overt aggression, dominance testing; Miller 1967; Isbell 1991) as well as scramble competition (e.g., foraging effort in group-living animals; Van Schaik and Van Noordwijk 1988; Shaw et al. 1995) and even reproductive conflict over offspring production in plural breeding species $(\mathrm{Ru}-$ benstein 2012; Shen et al. 2012). Importantly, we define an individual's contribution to social conflict in our model as competitive effort, $z$. To understand how social conflict is influenced by group size, we examine how an individual's competitive effort varies with group size and group productivity (i.e., the total reproductive output influenced by the group resources; see also Frank 1995, 2003). We assume that group productivity, $g\left(z_{1}, z_{2}, \ldots, z_{n}, n\right)$, is a function of group size and that each group member's share of the group productivity will increase as their level of competitive effort, $z$, increases. We further assume that competitive effort will not only have a negative impact on the group productivity itself but also on an individual's future fitness because there is a personal cost to exerting competitive effort (Rubenstein and Shen 2009).

Building on the framework of Frank (1995; see also Reeve et al. 1998), we investigate the tension between group productivity and individual competition for a share of that group productivity as group size varies. The fitness function of a focal individual $i$ in a group of size $n, w_{i}$ is

$$
\begin{aligned}
w_{i}\left(z_{1}, z_{2}, \ldots, z_{n}, n\right)= & g\left(z_{1}, z_{2}, \ldots, z_{n}, n\right) \\
& \times \frac{z_{i}}{\sum_{j=1}^{n} z_{j}}-c\left(z_{i}\right),
\end{aligned}
$$

where $c\left(z_{i}\right)$ is the personal cost of the competitive effort $z_{i}$ and $g\left(z_{1}, z_{2}, \ldots, z_{n}, n\right)$ is the group productivity function. Importantly, our formulation differs from those of Frank $(1995,1998)$ and subsequent authors (Foster 2004) in that we include the personal cost of social conflict (Rubenstein and Shen 2009). We assume that the cost function satisfies two sets of conditions: (i) $\partial g / \partial z_{i}<0$ and $\partial^{2} g / \partial z_{i}^{2} \leq 0$, which represent group productivity as a decreasing and linear or accelerating function of a focal individual's competitive effort; and (ii) $\partial c / \partial z_{i}>0$ and $\partial^{2} c / \partial z_{i}^{2}>0$, which imply that the proportional personal cost is an increasing and accelerating function of a focal individual's competitive effort (Trivers 1972).

We consider a population where individuals are genetically related to each other, which we characterize by the (demographically scaled) relatedness coefficient $r$ (Lehmann and Rousset 2010; Akçay and Van Cleve 2012). In general, this scaled relatedness coefficient will be a function of variables such as migration rate and group size. For example, in the island model with overlapping generations, relatedness scales as $2(1-m) s /\{n[2-m(1-s)]+2(1-$ $m) s\}$, where $m$ and $s$ are the migration rates between groups and survivorship, respectively (Taylor and Irwin 2000; Akçay and Van Cleve 2012). In different biological

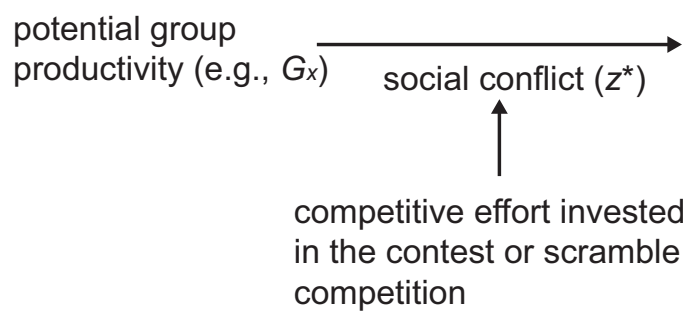

observed group

productivity (e.g., $\left.G_{x}-n z^{*}\right)$

Figure 1: Summary of the theoretical framework of our model 
scenarios, relatedness will vary with group size in different ways, though in general, it is expected to decrease with increasing group size. We further assume that individuals' competitive efforts are "sealed bid" efforts or that they do not respond to each other's behavior (Akçay and Van Cleve 2012). Given these assumptions, the evolutionarily stable level of competitive effort in a monomorphic population must satisfy

$\frac{\partial w_{i}}{\partial z_{i}}+(n-1) r \frac{\partial w_{i}}{\partial z_{j}}=0$ for $j \neq i$ and $z_{i}=z_{j}=z^{*}$.

For simplicity, we present the analysis for nonkin groups (i.e., $r=0$ ) here, but we also present the full analysis of the model in the appendix. Combining equations (1) and (2), after some rearrangement, we obtain

$$
\frac{\partial(g / n)}{\partial z_{i}}+\frac{(g / n)(n-1)}{n z^{*}}-\frac{\partial c}{\partial z_{i}}=0 .
$$

To understand how the evolutionarily stable level of competitive effort, $z^{*}$, changes with group size, we consider how each of the three terms changes with $n$. The first term in equation (3), the change in per capita group productivity with the competitive effort $z_{i}$, is negative since competition decreases group production. This term represents the share of the marginal cost of competition to the group that accrues to a single (in this case, the focal) individual. The second term is always positive and can be interpreted as the marginal benefit to the focal individual to invest in competition; the numerator is the total of the group productivity accruing to everyone but the focal individual, while the denominator reflects the fact that the "pie" is divided according to relative competitive effort. Finally, the third term reflects a private cost that is negative and independent of $n$. In other words, equation (3) says that competitive effort will increase with $n$ if the marginal cost of competition to the per capita group productivity (i.e., the first term) increases more slowly than the marginal incentive to invest in competition. Both terms are ultimately determined by how the per capita group productivity changes with group size. Thus, per capita productivity is the crucial quantity in determining the variation in social conflict as a function of group size.

Finally, in the appendix, we analyze this general model systematically and find that the evolutionarily stable level of competitive effort $\left(z^{*}\right)$ will increase with group size if the increase in per capita productivity is above a threshold but otherwise decrease. In other words, (i) social conflict can either increase or decrease with group size, and (ii) per capita group productivity is an important determinant of this social conflict-group size relationship. Below, we illustrate these general results with specific group productivity-group size functions.

\section{Examples with Specific Productivity Functions}

To explore how different ecological and social conditions impact social conflict, we focus on three specific productivity-group size functions that illustrate the range of variation observed in nature (fig. $2 A, 2 B$; Krause and Ruxton 2002). Importantly, these cases illustrate three of the primary reasons why animal social groups form, but they will differ in how potential total group productivity (i.e., the total reproductive output if all group resources are used for reproduction without engaging in social conflict) and potential per capita productivity vary with group size. When groups form (i) to gain access to critical fixed group resources, potential group productivity is unaffected by group size, but potential per capita productivity decreases as group size increases. However, when groups form (ii) to receive social benefits through group living, both potential group productivity and per capita productivity will initially increase as group size increases. However, both measures of productivity may decrease as group size increases further due to the detrimental effect of grouping. Finally, when groups form (iii) to enhance resource acquisition (e.g., territorial defense), potential group productivity will still increase as group size increases, but potential per capita productivity will decrease with increasing group size (Alexander 1974; Emlen 1982; Koenig et al. 1992; Queller and Strassmann 1998).

Access to Critical Fixed Group Resources. Using equation (1), the fitness function of a focal individual in groups that form to gain access to critical fixed resources (represented in fig. 2 by $G_{1}$ ) becomes

$$
w_{i}=\left[g_{0}-z_{i}-(n-1) z_{j}\right] \frac{z_{i}}{z_{i}+(n-1) z_{j}}-a z_{i}^{2} .
$$

Equation (4) makes explicit an important distinction between "potential" and "observed" group productivity. Potential group productivity, given by $g_{0}$ in equation (4), and its relation to the group size is important in determining social conflict (see also Frank 1995, 2003). In contrast, observed group productivity (i.e., $\left[g_{0}-z_{i}-(n-1) z_{j}\right]$ in eq. [4]) is the actual outcome of expending part of the group resources in social conflict. Importantly, observed group productivity can be directly measured in nature, whereas the measure of potential group productivity must account for the loss of group production to social conflict (e.g., must measure the total number of offspring produced prior to infanticide occurring; Ratnieks et al. 2006; Rankin et al. 2007; Bourke 2011).

In equation (4), potential group productivity (i.e., $g_{0}$ ) is unaffected by group size (fig. $2 A$ ), but potential per capita productivity (i.e., $g_{0} / n$ ) decreases as group size increases (fig. 2B). Examples of this type of group produc- 

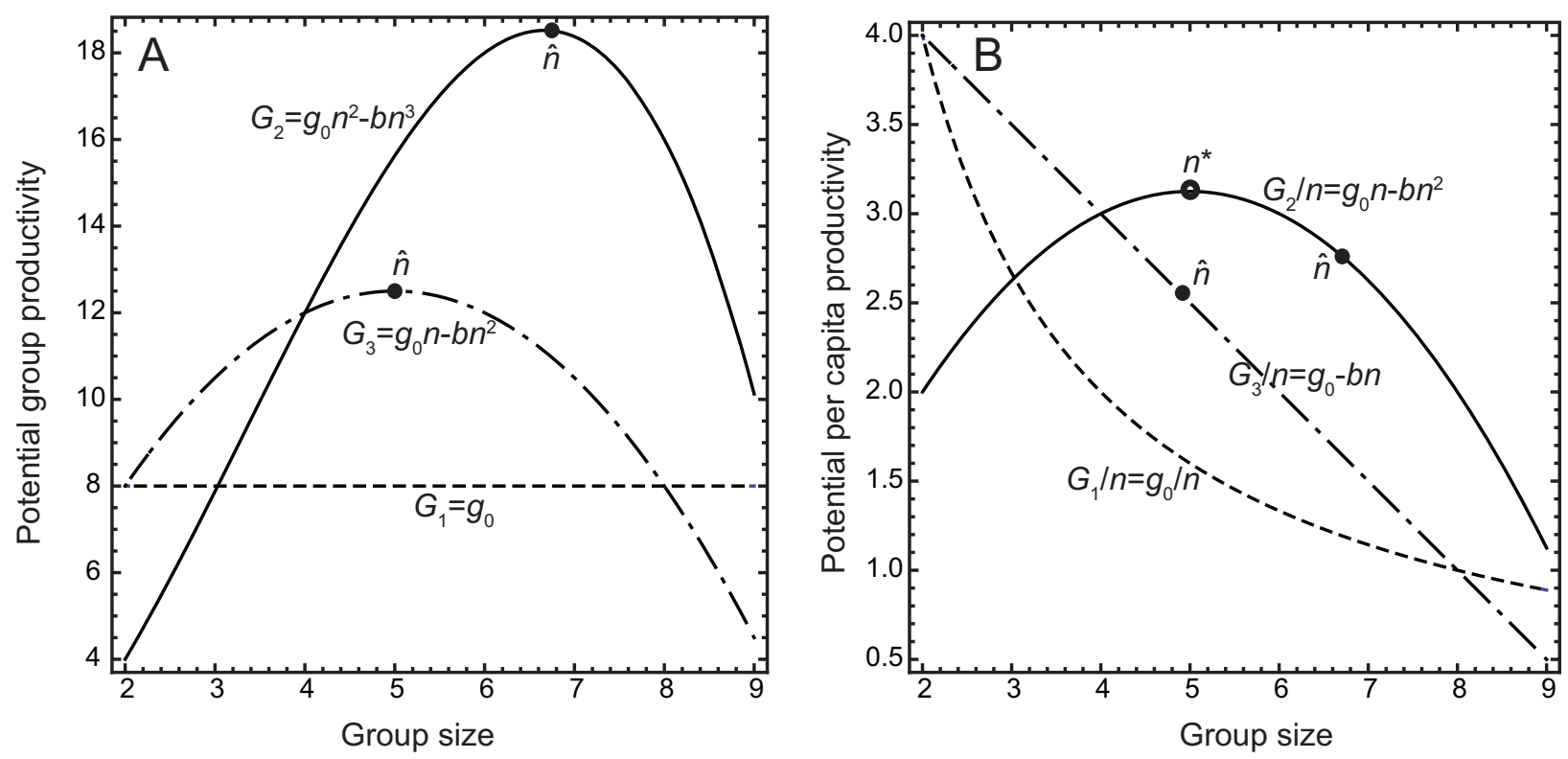

Figure 2: Examples of the relationships between group size and potential group productivity (i.e., group productivity in the absence of competition; $A$ ) and potential per capita productivity $(B)$. Parameters $g$ and $b$ are scaling factors for describing different shapes of the group productivity and group size functions, and $n$ represents group size. The term $\hat{n}$ represents the group size with maximum potential group productivity, and $n^{*}$ indicates the group size of maximum potential per capita productivity. $G_{1}, G_{2}$, and $G_{3}$ indicate different potential group size-group productivity functions. Parameter vales are $g_{0}=8$ for $G_{1}, g=1.25$ and $b=0.125$ for $G_{2}$, and $g_{0}=5$ and $b=0.5$ for $G_{3}$.

tivity function include the burying beetle example mentioned earlier as well as artificial groups, such as captive farm animals where individuals often compete for limited resources (e.g., food, water, attractive laying areas; Andersen et al. 2004).

Using the first order condition for evolutionary stability (eq. [2]), we find the evolutionarily stable level of competitive effort when group production is given by equation (4) to be

$$
z_{i}^{*}=\frac{\sqrt{n^{2}\left[n^{2}-8 a g_{0}(n-1)(r-1)\right]}-n^{2}}{4 a n^{2}} .
$$

This equation predicts that $z_{i}^{*}$ decreases with $n$ (fig. $3 A$, dashed line; see also "Results and Discussion"). Additionally, this level of conflict will be convergence stable (i.e., fixation of successive mutations will move the population closer to the evolutionarily stable level of competitive effort; Eshel and Motro 1981; Christiansen 1991) when the following condition holds: $\left(d / d z^{*}\right)\left[\left(\partial w_{i} / \partial z_{i}\right)+r(n-\right.$ 1) $\left.\left(\partial w_{i} / \partial z_{j}\right)\right]<0$ and $z_{i}=z_{j}=z^{*}$. Furthermore, it can be verified that within the relevant range of relatedness (i.e., $r<1$ ), a necessary and sufficient condition for convergence stability is $r<1 /(n-1)$.

Social Benefits of Group Living. In groups that form because of the benefits of sociality per se, such as cooper- atively breeding lions, cooperatively hunting groups, or even flocks of birds (represented in fig. 2 by $G_{2}$ ), we expect both potential group productivity and per capita productivity to increase initially as group size increases (fig. 2). However, both measures of productivity may decrease as group size increases further due to the detrimental effect of grouping (e.g., inefficiency of utilizing group-enhancing resources or other factors that negatively influence fitness such as parasite loads). Similarly, applying equation (1), the fitness function of a focal individual in groups that form for social benefit is

$$
\begin{aligned}
w_{i}= & {\left[g_{0} n^{2}-b n^{3}-z_{i}-(n-1) z_{j}\right] } \\
& \times \frac{z_{i}}{z_{i}+(n-1) z_{j}}-a z_{i}^{2} .
\end{aligned}
$$

The evolutionarily stable level of competitive effort in this case is

$$
z_{i}^{*}=\frac{\sqrt{1+8 a(n-1)\left(g_{0}-b n\right)(1-r)}-1}{4 a} .
$$

This result shows that $z_{i}^{*}$ can either increase or decrease with $n$ (fig. $3 A$, solid line; see also "Results and Discussion"). This level of conflict will also be convergence stable within the relevant range of parameter space (i.e., $g_{0}>$ $b n, n>1$, and $r>0$ ). 

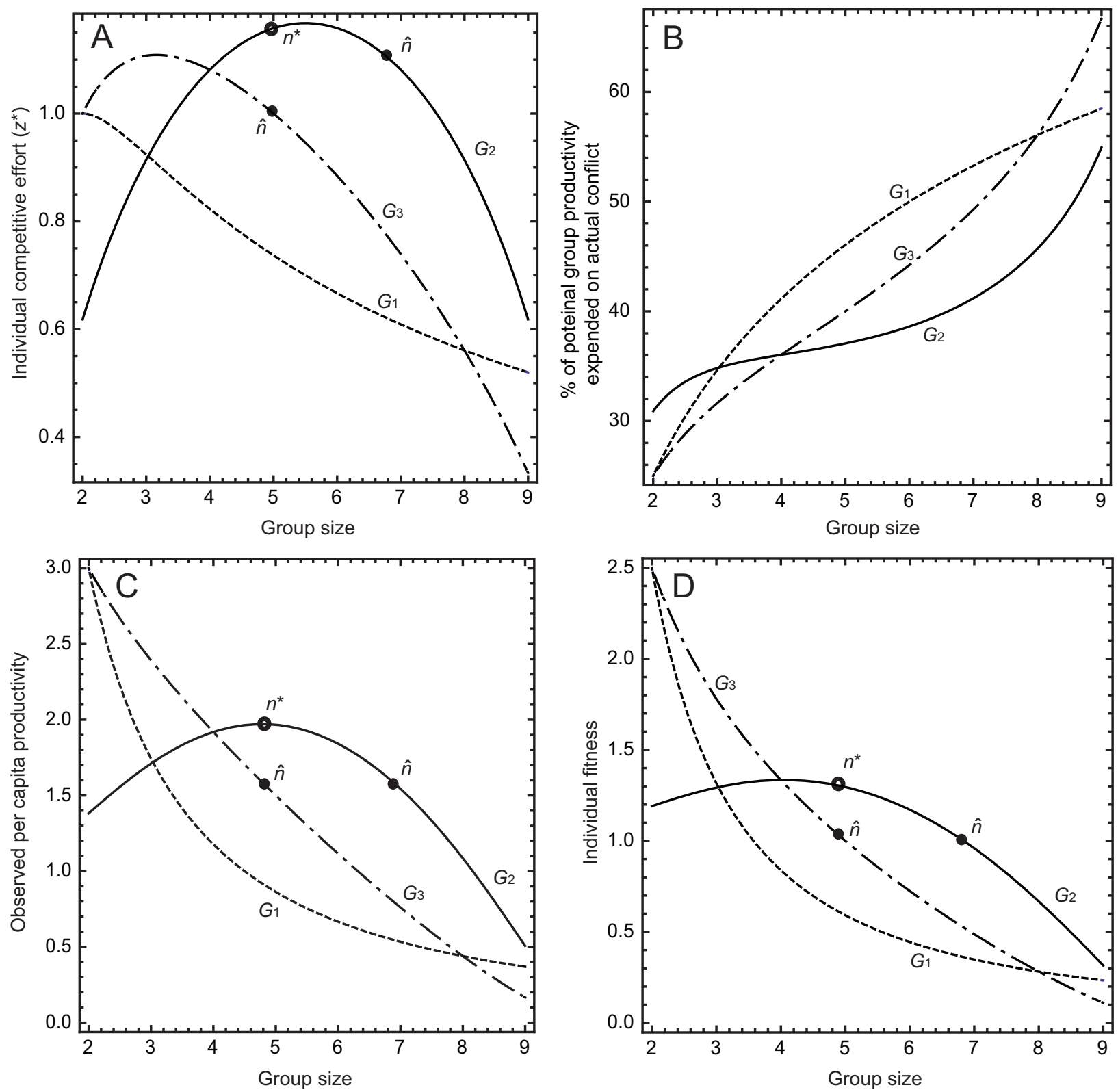

Figure 3: Results of variation group size $(n)$ with individual competitive effort $\left(z^{*} ; A\right)$; percentage of potential group productivity expended on social conflict $(B)$; observed per capita productivity, $\left(\left.G_{x}\right|_{x=1,2,3}-n z^{*}\right) / n(C)$; and individual fitness, which is $w_{i}=\left(\left.G_{x}\right|_{x=1,2,3}-\right.$ $\left.n z^{*}\right) / n-c\left(z^{*}\right)(D)$, where $c(z)=a z^{2}$. The term $\hat{n}$ represents the group size with maximum potential group productivity, and $n^{*}$ indicates the group size of maximum potential per capita productivity. $G_{1}, G_{2}$, and $G_{3}$ indicate different potential group size-group productivity functions. All graphs assume $r=0$ and $a=0.5$.

Resource Acquisition. When groups form to improve resource acquisition (represented in fig. 2 by $G_{3}$ ), potential group productivity could still increase as group size increases (fig. $2 A$ ), but potential per capita productivity will decrease with increasing group size (fig. $2 B$ ). This occurs because the enhancement of resource acquisition through grouping is not large enough to benefit every group member. This pat- tern occurs in many cooperatively breeding birds, where social groups often form because suitable breeding territories are not available and having helpers will lead to increased group productivity but reduced per capita productivity (Stacey and Koenig 1990; Koenig and Dickinson 2004). The fitness function of a focal individual in groups that form for resource acquisition is described as 


$$
\begin{aligned}
w_{i}= & {\left[g_{0} n-b n^{2}-z_{i}-(n-1) z_{j}\right] } \\
& \times \frac{z_{i}}{z_{i}+(n-1) z_{j}}-a z_{i}^{2} .
\end{aligned}
$$

The evolutionarily stable level of competitive effort is

$$
z_{i}^{*}=\frac{\sqrt{n\left[n+8 a(n-1)\left(g_{0}-b n\right)(1-r)\right]}-n}{4 a n} .
$$

As in equation (7), this result shows that $z_{i}^{*}$ can either increase or decrease with $n$ (fig. $3 A$, dotted-dashed line). As before, this level of conflict will be convergence stable within the relevant range of parameter space (i.e., $g_{0}>b n, n>1$, and $r>0)$.

\section{Results and Discussion}

Our model has three primary results. First, social conflict (i.e., costly competitive efforts of individuals, $z^{*}$ ) can either increase or decrease as group size increases. Second, the relationship between group productivity and group size plays a critical role in determining the direction of this relationship (fig. 3A). Third, the proportion of (potential) group productivity expended on social conflict (i.e., $n z^{*} / G_{x}$ ) typically increases with increasing group size (fig. $3 B$ ). In general, an individual's competitive effort will typically increase as potential per capita productivity increases with group size, but it will decrease as per capita productivity decreases with group size (fig. $3 A$; but see also inequality [A4] in the appendix for the general relationship). The intuition behind this result is simply that the marginal benefit of competitive behavior increases with the per capita productivity of the group as group size increases, resulting in higher incentives to engage in conflict. This relatively simple prediction of our model and the intuition behind it have important consequences for understanding social conflict in animal societies.

We explored this result further by considering three specific models for how animals benefit from living in groups that form for different reasons. For groups that form primarily to access critical resources, such as burying beetles, many cooperatively breeding birds and animals living in artificial groups (described by $G_{1}$, if individuals do not produce or defend the resource socially, or by $G_{3}$, if resources are a more important determinant of productivity than sociality itself), per capita productivity is likely to decrease as group size increases (Koenig and Dickinson 2004). We demonstrate that in these cases, it is more likely that the evolutionarily stable level of competitive effort will decrease with increasing group size. In support of this prediction, social aggression has been shown to decrease with increasing group size in many groups of farm animals (reviewed in Andersen et al. 2004). Alternatively, if groups form primarily because of the fitness benefits associated with living socially with others per se, then we expect a hump-shaped fitness-group size relationship, as has been observed in many cooperatively breeding mammals (Solomon and French 1997) and eusocial insects (Choe and Crespi 1997). Consequently, social conflict is predicted to increase with increasing group size until group size is larger than the most productive size in these species. This relationship occurs in stenogastrine wasps, where social aggression was positively correlated with the total number and per capita number of brood (Fanelli et al. 2008), as well as in bumblebees Bombus terrestris, where the frequency of aggressions in both $\alpha$ - and $\beta$-workers increased with increasing group size (Amsalem and Hefetz 2011).

Our results also show that observed per capita productivity, individual fitness, and potential per capita productivity still have similar relationships with group size, due to the adjustment of an individual's competitive effort (fig. $3 C, 3 D)$. As we pointed out earlier, although potential group productivity is an important parameter in determining levels of social conflict, most empirical studies measure the observed as opposed to potential group productivity. Because our model shows that potential group productivity and observed group productivity have a qualitatively similar relationship with group size, it provides a theoretical basis for understanding the relationship between group size and social conflict when only observed group productivity is available. Finally, it is important to point out that social conflict was predicted to increase with decreasing group productivity in a previous, non-gametheoretical model (Reeve and Nonacs 1997). However, this model did not consider variation in group productivity with group size, as we have done here. Although additional empirical studies are clearly needed to test the different predicted relationships among group productivity, group size, and social conflict in social animals, our model's predictions are consistent with empirical data from a diverse array of taxa.

Our model also predicts that a larger proportion of potential group productivity will be expended in social conflict (i.e., $n z^{*} / G_{x}$ ) as group size increases (fig. $3 B$ ), despite the fact that per capita competitive effort $\left(z^{*}\right)$ might decrease (fig. $3 A$ ), simply because there are more individuals competing and therefore consuming the group resources. Both competitive effort $\left(z^{*}\right)$ and standardized competitive effort $\left(n z^{*} / G_{x}\right)$ can be viewed as measures of social conflict. We suggest that the absolute effort (e.g., the frequency of aggressions) would be a better measure for understanding the fitness consequences of social conflict in intraspecific studies where actual numbers of offspring (or resources) lost can be compared across groups. In contrast, the standardized competitive effort (e.g., the 

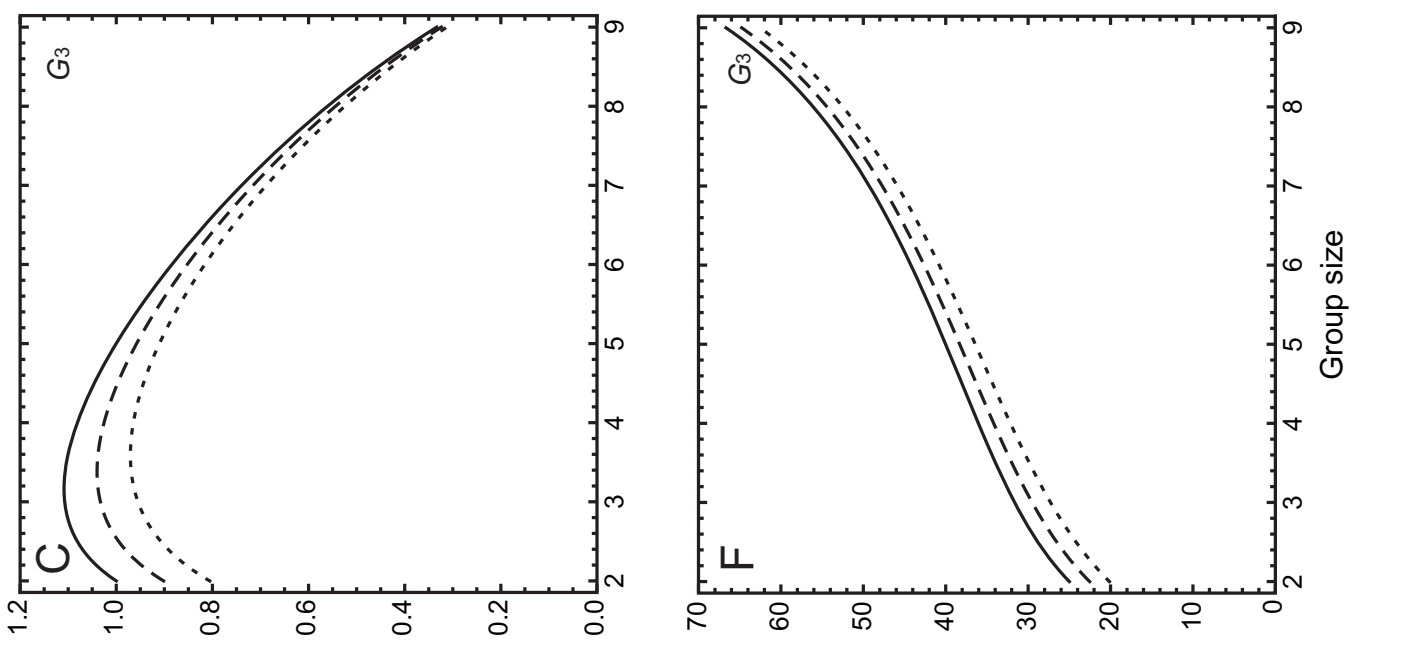

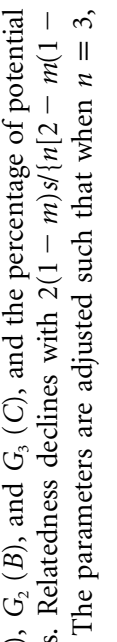
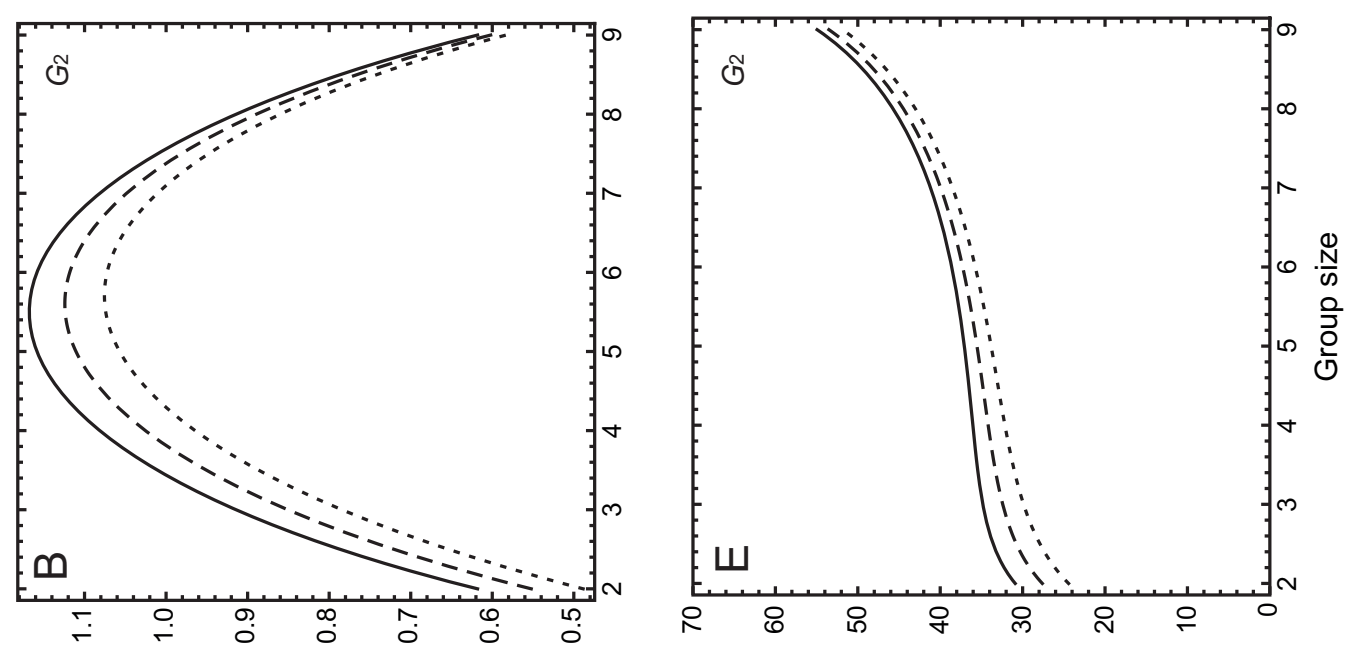

过

$\Xi \Xi$

실

过 흥

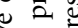

窇产

द्वे :

을 웅

to

․ㅛㅁ

50

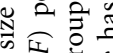

:

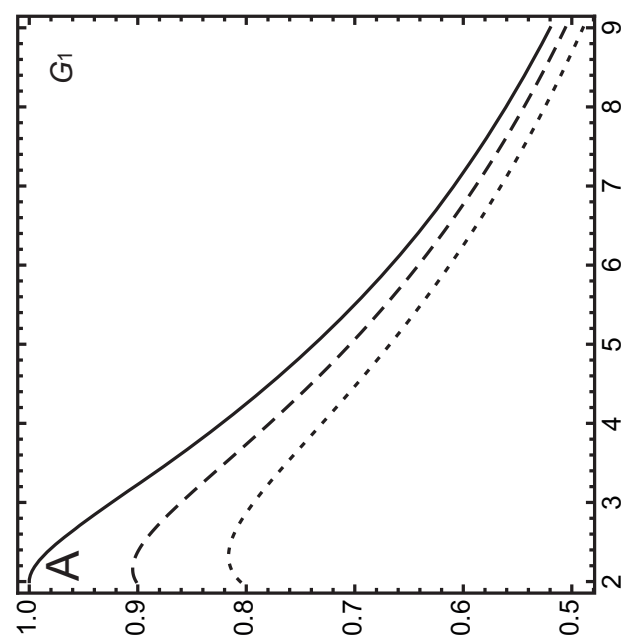

$\left.{ }_{*} z\right)$ นонә әк!!!!ədயоว

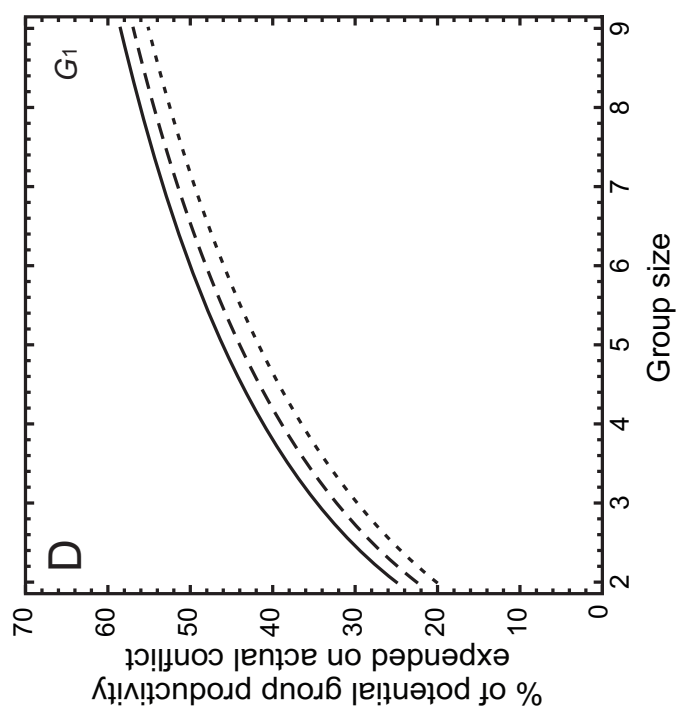

चै जี

की

ज证

㝎蔫

जิ जी

का $\Xi$ ? ?

氙. 흡

สิ

西䒓

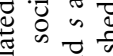

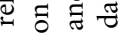

过跤

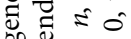

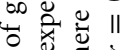

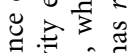

氖管

$\Xi \tilde{D}$

$\ddot{\forall}$

空等:

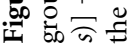


percentage of eggs destroyed) is more suitable for comparative studies examining conflict resolution (i.e., the reduction of group resources expended on actual conflict) among different species (e.g., Ratnieks et al. 2006; fig. 3) because it provides a standard measure of social conflict for animals with different life histories. We envision that systems where potential group productivity is easier to measure, such as cooperatively breeding vertebrates that exhibit infanticide or egg tossing (Mumme et al. 1983; Young and Clutton-Brock 2006) or social insects that exhibit egg eating (Wenseleers and Ratnieks 2006), will be especially suitable for testing the predictions of our model and for understanding the nature of social conflict and conflict resolution.

Finally, we find that, not surprisingly, genetic relatedness can moderate the level of social conflict in a group, but even genetically related individuals will be in conflict (fig. $4 A-4 C$ ). Additionally, smaller proportions of potential group productivity will be expended on social conflict among more closely related group members (fig. $4 D-4 F$ ). However, relatedness does not qualitatively change the predictions of the model about how group productivity and group size influence social conflict (see appendix for the general analysis). The predictions of the model, such as how group productivity and group size influence social conflict, are qualitatively similar in groups with different average relatedness among group members (fig. 4).

In summary, determining how social conflict varies with group size is vital for understanding animal social evolution. Here we highlight the importance of identifying different group size-group productivity relationships in examining how social conflict varies with group size. Our model shows that social conflict should not be automatically assumed to increase with group size. Instead, natural selection adjusts competitive efforts in response to both group productivity and group size. To illustrate the range of expected outcomes, we present alternative scenarios for how conflict might vary with group size for groups that form for different reasons. For example, in most cooperatively breeding birds and farm animals living in artificial groups, where groups typically have limited critical resources, social conflict is predicted to decrease as group size increases. In contrast, in most social insects and cooperatively breeding mammals where groups form due to the benefits of associating with greater numbers of individuals, a positive relationship between group size and social conflict is predicted. Our model thus provides a simple but general ecological explanation for various forms of social conflict and group size relationships in a diverse array of complex animal societies. Moreover, it can be applied to a range of social phenomenon, including social stress, sibling competition, and within-group conflict in cooperative breeders and social foragers.

\section{Acknowledgments}

S.-F.S. was funded by Academia Sinica (Career Development Award) and the National Science Council of Taiwan (1002621-B-001-004). D.R.R. was supported by the National Science Foundation (IOS-1121435 and IOS-1252946), as was E.A. (EF-1137894 to S. A. Levin).

\section{APPENDIX}

\section{Analysis of the General Model}

The fitness function of a focal individual, $w_{i}$, in a group of size $n$, as described in the main article, is

$$
w_{i}\left(z_{1}, z_{2}, \ldots, z_{n}, n\right)=g\left(z_{1}, z_{2}, \ldots, z_{n}, n\right) \frac{z_{i}}{\sum_{j=1}^{n} Z_{j}}-c\left(z_{i}\right) .
$$

The evolutionarily stable level of competitive effort must then satisfy equation (2) in the main text. Since equation (2) holds for all values of $n$ and $z$, we can differentiate with respect to $n$ to obtain, after some rearrangement,

$$
\frac{\partial z^{*}}{\partial n}=\frac{z\left[A-n z^{*}\left(n\left\{[1+(n-1) r] g_{z_{i} n}-n r c^{\prime}\right\}-(1-r) g_{z_{i}}-n(n-1)\left(g-n g_{z_{i}} z^{*}\right) r^{\prime}\right)\right]}{n[1+(n-1) r]\left(n z^{*}\left\{(n-1) g_{z_{i}}+z^{*}\left[g_{z_{i}, z_{i}}+(n-1) g_{z_{i}, z_{j}}-n c^{\prime \prime}\right]\right\}-g(n-1)\right)},
$$

where $A=g\{[n(n+1)-2] r-(n-2)\}+g_{n} n(n-1)(1-r)$ and the subscripts on $g$ denote the partial derivatives with respect to the variables in the subscripts. Additionally, we have taken advantage of the assumption that the group productivity is symmetric in all $z_{i}$. Note that we allow the scaled relatedness $r$ to be a function of the group size.

Given the assumptions described in the main text, all the terms in the denominator of $\partial z^{*} / \partial n$, except for the one involving $g_{z_{i}, z_{j}}$, are negative. For now, assume that $g_{z_{\mathfrak{j}} z_{j}}$ is small enough that the whole denominator is negative. In this case, the sign of $\partial z^{*} / \partial n$, which represents whether social conflict will increase or decrease with group size, will be 
determined by its numerator. Since we are interested in how per capita productivity $(g / n)$ influences an individual's competitive effort, we rearrange the numerator of $\partial z^{*} / \partial n$ to obtain

$$
\frac{\partial z^{*}}{\partial n}>0 \text {, if } \frac{\partial(g / n)}{\partial n}>\frac{g\left[\left(n^{2}-1\right) r+1\right]+n z^{*}\left(n\left\{[1+(n-1) r] g_{z_{i, n}}-n r c^{\prime}\right\}-(1-r) g_{z_{i}}\right)-n(n-1)\left(g-n g_{z_{i}} z^{*}\right) r^{\prime}}{(1-r)(n-1) n^{2}} .
$$

Inequality (A3) simplifies, if one considers interactions among unrelated individuals (i.e., where the evolutionarily stable level of competitive effort is expected to be highest), to become

$$
\frac{\partial z^{*}}{\partial n}>0, \text { if } \frac{\partial(g / n)}{\partial n}>\frac{g(n-2)+n\left(g_{z_{i}}-n g_{z_{i} n}\right) z^{*}}{n(n-1)} .
$$

These inequalities suggest that faster increases (or slower decreases) of per capita productivity with group size tend to promote a concomitant increase in social conflict. This occurs because condition (A2) becomes easier to satisfy. However, when the denominator in (A2) becomes positive, the inequality in condition (A4) will be reversed, meaning that faster increases in per capita productivity will promote a slower increase (or decrease) in social conflict. Moreover, if the marginal decrease in group productivity with competitive effort is a sufficiently fast decreasing function of others' competitive efforts (i.e., a high enough cross derivative $g_{z_{i} z_{j}}$ ), then inequality (A4) can be reversed. This might happen when small total competitive efforts decrease group productivity so much that later competition cannot decrease it further (i.e., if group productivity requires a very low level of discord). In such a case, many of the relations considered here would also be reversed. Because there is little data available on how individuals' competitive interactions interact with each other in reducing group productivity, more empirical effort on this issue is needed.

\section{Literature Cited}

Akçay, E., and J. Van Cleve. 2012. Behavioral responses in structured populations pave the way to group optimality. American Naturalist 179:257-269.

$\rightarrow$ Alexander, R. D. 1974. The evolution of social behavior. Annual Reviews in Ecology and Systematics 5:325-383.

$\rightarrow$ Amsalem, E., and A. Hefetz. 2011. The effect of group size on th $\rightarrow$ interplay between dominance and reproduction in Bombus terrestris. PLoS ONE 6:e18238.

$\rightarrow$ Andersen, I. L., E. Nævdal, M. Bakken, and K. E. Bøe. 2004. Ag gression and group size in domesticated pigs, Sus scrofa: "when the winner takes it all and the loser is standing small." Animal Behaviour 68:965-975.

Bourke, A. F. G. 2011. Principles of social evolution. Oxford Uni $\rightarrow$ versity Press, Oxford.

Calcott, B., and K. Sterelny. 2011. The major transitions in evolutior $\rightarrow$ revisited. MIT Press, Cambridge, MA.

$\rightarrow$ Cant, M. A. 2012. Suppression of social conflict and evolutionar $\rightarrow$ I transitions to cooperation. American Naturalist 179:293-301.

Choe, J. C., and B. J. Crespi. 1997. The evolution of social behavior in insects and arachnids. Cambridge University Press, Cambridge -

$\rightarrow$ Christiansen, F. B. 1991. On conditions for evolutionary stability for a continuously varying character. American Naturalist 138:37-50.

$\rightarrow$ Clutton-Brock, T., S. Hodge, and T. Flower. 2008. Group size and the suppression of subordinate reproduction in Kalahari meerkats. Animal Behaviour 76:689-700.

Eggert, A. K., and J. K. Muller. 1997. Biparental care and social evolution in burying beetles: lessons from the larder. Pages 216236 in J. C. Choe and B. J. Crespi, eds. The evolution of social behavior in insects and arachnids. Cambridge University Press, Cambridge. $\rightarrow$ Emlen, S. T. 1982. The evolution of helping. I. An ecological constraints model. American Naturalist 119:29-39.

$\rightarrow$ Eshel, I., and U. Motro. 1981. Kin selection and strong evolutionary stability of mutual help. Theoretical Population Biology 19:420433.

$\rightarrow$ Fanelli, D., J. J. Boomsma, and S. Turillazzi. 2008. Subordinate wasps are more aggressive in colonies with low reproductive skew. Animal Behaviour 75:879-886.

Foster, K. R. 2004. Diminishing returns in social evolution: the notso-tragic commons. Journal of Evolutionary Biology 17:10581072.

Frank, S. A. 1995. Mutual policing and repression of competition in the evolution of cooperative groups. Nature 377:520-522.

. 1998. Foundations of social evolution. Princeton University Press, Princeton, NJ.

2003. Perspective: repression of competition and the evolution of cooperation. Evolution 57:693-705.

Godfray, H. C. J. 1995. Evolutionary theory of parent-offspring conflict. Nature 376:133-138.

Isbell, L. A. 1991. Contest and scramble competition: patterns of female aggression and ranging behavior among primates. Behavioral Ecology 2:143-155.

Johnstone, R. A. 2000. Models of reproductive skew: a review and synthesis. Ethology 106:5-26.

Koenig, W. D., and J. L. Dickinson. 2004. Ecology and evolution of cooperative breeding in birds. Cambridge University Press, Cambridge.

$\rightarrow$ Koenig, W. D., F. A. Pitelka, W. J. Carmen, R. L. Mumme, and M. T. Stanback. 1992. The evolution of delayed dispersal in cooperative breeders. Quarterly Review of Biology 67:111-150.

Krause, J., and G. D. Ruxton. 2002. Living in groups. Oxford University Press, Oxford.

$\rightarrow$ Lehmann, L., and F. Rousset. 2010. How life history and demography 
promote or inhibit the evolution of helping behaviours. Philo sophical Transactions of the Royal Society B: Biological Sciences 365:2599-2617.

Maynard-Smith, J., and E. Szathmary. 1997. The major transition in evolution. Oxford University Press, Oxford.

$\rightarrow$ Mileva, V. R., J. L. Fitzpatrick, S. Marsh-Rollo, K. M. Gilmour, C. M. Wood, and S. Balshine. 2009. The stress response of the highl; social African cichlid Neolamprologus pulcher. Physiological and Biochemical Zoology 82:720-729.

$\rightarrow$ Miller, R. S. 1967. Pattern and process in competition. Advances ir Ecological Research 4:1-74.

$\rightarrow$ Monnin, T., F. L. W. Ratnieks, and C. R. F. Brandão. 2003. Reproductive conflict in animal societies: hierarchy length increases with colony size in queenless ponerine ants. Behavioral Ecology anc Sociobiology 54:71-79.

$\rightarrow$ Mumme, R. L., W. D. Koenig, and F. A. Pitelka. 1983. Reproductive competition in the communal acorn woodpecker: sisters destro; each other's eggs. Nature 306:583-584.

$\rightarrow$ Queller, D. C., and J. E. Strassmann. 1998. Kin selection and social insects. BioScience 48:165-175.

$\rightarrow-$. 2009. Beyond society: the evolution of organismality. Philosophical Transactions of the Royal Society B: Biological Sciences 364:3143-3155.

$\rightarrow$ Rankin, D. J., K. Bargum, and H. Kokko. 2007. The tragedy of the commons in evolutionary biology. Trends in Ecology and Evolution 22:643-651.

$\rightarrow$ Ratnieks, F. L. W., K. R. Foster, and T. Wenseleers. 2006. Conflict resolution in insect societies. Annual Review of Entomology 51: 581-608.

$\rightarrow$ Ratnieks, F. L. W., and H. K. Reeve. 1992. Conflict in single-queen hymenopteran societies: the structure of conflict and processes tha reduce conflict in advanced eusocial species. Journal of Theoretical Biology 158:33-65.

$\rightarrow$ Reeve, H. K. 2000. A transactional theory of within-group conflict American Naturalist 155:365-382.

$\rightarrow$ Reeve, H. K., S. T. Emlen, and L. Keller. 1998. Reproductive sharing in animal societies: reproductive incentives or incomplete controby dominant breeders? Behavioral Ecology 9:267-278.

$\rightarrow$ Reeve, H. K., and B. Hölldobler. 2007. The emergence of a super organism through intergroup competition. Proceedings of the National Academy of Sciences of the USA 104:9736-9740.

$\rightarrow$ Reeve, H. K., and P. Nonacs. 1997. Within-group aggression and the value of group members: theory and a field test with social wasps. Behavioral Ecology 8:75-82.
Robertson, I. C., W. G. Robertson, and B. D. Roitberg. 1998. A model of mutual tolerance and the origin of communal associations between unrelated females. Journal of Insect Behavior 11:265-286.

Rubenstein, D. R. 2012. Family feuds: social competition and sexual conflict in complex societies. Philosophical Transactions of the Royal Society B: Biological Sciences 367:2304-2313.

Rubenstein, D. R., and S. F. Shen. 2009. Reproductive conflict and the costs of social status in cooperatively breeding vertebrates. American Naturalist 173:650-661.

Shaw, J. J., T. Tregenza, G. A. Parker, and I. F. Harvey. 1995. Evolutionarily stable foraging speeds in feeding scrambles: a model and an experimental test. Proceedings of the Royal Society B: Biological Sciences 260:273-277.

Shen, S.-F., and H. K. Reeve. 2010. Reproductive skew theory unified: the general bordered tug-of-war model. Journal of Theoretical Biology 263:1-12.

$\rightarrow$ Shen, S.-F., S. L. Vehrencamp, R. A. Johnstone, H.-C. Chen, S.-F. Chan, W.-Y. Liao, K.-Y. Lin, and H.-W. Yuan. 2012. Unfavourable environment limits social conflict in Yuhina brunneiceps. Nature Communications 3:885.

Solomon, N. G., and J. A. French. 1997. Cooperative breeding in mammals. Cambridge University Press, Cambridge.

Stacey, P. B., and W. D. Koenig. 1990. Cooperative breeding in birds: long-term studies of ecology and behavior. Cambridge University Press, Cambridge.

$\rightarrow$ Taylor, P. D., and A. J. Irwin. 2000. Overlapping generations can promote altruistic behavior. Evolution 54:1135-1141.

Trivers, R. L. 1972. Parental investment and sexual selection. Pages 136-179 in B. Campbell, ed. Sexual selection and the descent of man: 1871-1971. Aldine, Chicago.

$\rightarrow$ Van Schaik, C. P., and M. A. Van Noordwijk. 1988. Scramble and contest in feeding competition among female long-tailed macaques (Macaca fascicularis). Behaviour 105:77-98.

VanderWaal, K. L., A. Mosser, and C. Packer. 2009. Optimal group size, dispersal decisions and postdispersal relationships in female African lions. Animal Behaviour 77:949-954.

Wenseleers, T., and F. L. Ratnieks. 2006. Enforced altruism in insect societies. Nature 444:50.

Young, A. J., and T. Clutton-Brock. 2006. Infanticide by subordinates influences reproductive sharing in cooperatively breeding meerkats. Biology Letters 2:385-387.

Associate Editor: Stephen B. Heard Editor: Troy Day 